\title{
Sexo, igualdad, diversidad y leyes LGTBI*
}

\section{Sex, equality, diversity and LGTBI laws}

\author{
Paz M. de la Cuesta Aguado \\ Universidad de Cantabria \\ ORCID ID 0000-0001-5738-3776 \\ pazm.delacuesta@unican.es
}

\section{Cita recomendada:}

Cuesta Aguado, P. M. de la (2021). Sexo, igualdad, diversidad y leyes LGTBI. Eunomía. Revista en Cultura de la Legalidad, 20, pp. 141-154.

doi: https://doi.org/10.20318/eunomia.2021.6066

Recibido / received: 13/05/2020 Aceptado / accepted: 14/07/2020

\section{Resumen}

Desde 2012 se ha generado una interesante actividad legislativa sobre el colectivo LGTBI. Todas estas leyes intentan garantizar, con finalidad didáctica y voluntarismo, la igualdad y evitar la violencia y discriminación que padece el colectivo. Sin embargo, una ley estatal se hace necesaria ya que las leyes autonómicas son insuficientes y pueden generar situaciones de conflicto normativo. A continuación, se analizan algunos problemas de técnica jurídica y se reflexiona sobre la necesidad y oportunidad de medidas específicas de acción positiva, pues, sin tales medidas, las leyes no dejan de ser meros catálogos de buenas intenciones, salvo por los ya referidos efectos didácticos. Estas medidas de acción positiva son necesarias para la mejora de vida del colectivo, que también tendrán efectos directos beneficiosos en otros, como el de mujeres, y, en general, indirectamente en toda la sociedad.

\section{Palabras clave}

Igualdad, diversidad sexual, no discriminación, leyes LGTBI, vulnerabilidad.

\begin{abstract}
Since 2014, an interesting legislative activity has been generated on the LGTBI community. All these laws try to guarantee equality, with didactic and voluntary purposes in order to avoid violence and non-discrimination situations. However, a state law is necessary since regional laws are insufficient and it can be generated regulatory conflicts. Some legal technical questions are analyzed, as well as the absence of specific and courageous measures of positive action. However, without such measures, the laws are still catalogs of good intentions, except for the aforementioned didactic effects. These positive action measures are necessary to improve the life of the group, but it will have direct beneficial effects on other groups, such as women, and, in general, indirectly throughout society.
\end{abstract}

\footnotetext{
*Artículo realizado en el seno del PID2019-107974RB-100 «Derecho penal y distribución de la riqueza en la sociedad tecnológica».
} 


\author{
Keywords \\ Equality, sexual diversity, non-discrimination, LGTBI laws, vulnerability.
}

SUMARIO. 1. Sobre la necesidad y la oportunidad de las leyes LGTBI. 2. Impulso político y racionalidad jurídica. 2.1. Modalidades de leyes LGTBI. 2.2. Exceso competencial. 2.3. Carencias derivadas de la técnica jurídica utilizada. $2.4 \mathrm{El}$ problema terminológico. 2.4.1. Cuestiones generales. 2.4.2. Sobre el Título de la Ley y lo que ello conlleva. 3. Igualdad, no discriminación y acción positiva. 3.1. Medidas de acción positiva en el acceso al empleo público. 3.2. Sobre las pruebas físicas vinculadas al sexo biológico. 3.3. De la acción positiva en el deporte. 4. Reflexiones finales y sobre la necesidad de la identificación del propio sexo.

\title{
1. Sobre la necesidad y la oportunidad de las leyes LGTBI
}

Desde 2012, algunas autonomías han dictado en el ámbito de sus competencias leyes dirigidas al reconocimiento expreso y protección de derechos de las personas que pertenecen al colectivo de personas lesbianas, gais, transexuales, bisexuales e intersexuales (LGTBI) -y alguna otra ha iniciado la tramitación parlamentaria ${ }^{1}$-, en tanto que, en el ámbito estatal, se han presentado, con escaso éxito, diversas iniciativas ante el Parlamento ${ }^{2}$. Con independencia de lo controvertida (o no) que pueda ser la aprobación de estas leyes, y salvando las diferencias competenciales entre las leyes autonómicas y la non nata ley estatal, todas ellas comparten algunos problemas comunes en torno a los que gira esta reflexión.

Antes de entrar en el contenido de las diversas leyes, cabe detenerse sobre su necesidad, por dos motivos: primero, porque son leyes que, salvo en lo relacionado con el reconocimiento de nuevos derechos y prestaciones a las personas trans, dedican una gran parte de su articulado a reconocer o promover derechos que todas las personas tienen reconocidos en España y, segundo, porque, en relación con las leyes que están en estos momentos tramitándose en vía parlamentaria, incluso

\footnotetext{
1 Este es el caso de la Comunidad Autónoma de Cantabria, con el Proyecto de Ley de Cantabria de garantía de derechos de las personas lesbianas, gais, trans, transgénero, bisexuales e intersexuales y no discriminación por razón de orientación sexual e identidad de género, remitido por el Gobierno (Boletín Oficial del Parlamento de Cantabria de 13 de diciembre de 2019). Finalmente, y tras el correspondiente procedimiento parlamentario, vio la luz como Ley 8/2020, de 11 de noviembre, de Garantía de Derechos de las Personas Lesbianas, Gais, Trans, Transgénero, Bisexuales e Intersexuales y No Discriminación por Razón de Orientación Sexual e Identidad de Género (Boletín Oficial del Estado de 10 de diciembre de 2020).

2 Así, la Proposición de Ley contra la discriminación por orientación sexual, identidad o expresión de género y características sexuales, y de igualdad social de lesbianas, gais, bisexuales, transexuales, transgénero e intersexuales, presentada por el Grupo Parlamentario Confederal de Unidos Podemos-En Comú Podem-En Marea (Boletín Oficial de las Cortes Generales de 12 de mayo de 2017) o la Proposición de Ley sobre la protección jurídica de las personas trans y el derecho a la libre determinación de la identidad sexual y expresión de género, presentada por el Grupo Parlamentario Confederal de Unidos Podemos-En Comú Podem-En Marea (Boletín Oficial de las Cortes Generales de 2 de marzo de 2018). También, la Proposición de Ley para la reforma de la Ley 3/2007, de 15 de marzo, reguladora de la rectificación registral de la mención relativa al sexo de las personas, para permitir la rectificación registral de la mención relativa al sexo y nombre de los menores transexuales y/o trans, para modificar exigencias establecidas en el artículo 4 respecto al registro del cambio de sexo, y para posibilitar medidas para mejorar la integración de las personas extranjeras residentes en España, presentada por el Grupo Parlamentario Confederal de Unidos Podemos-En Comú Podem-En Marea (Boletín Oficial de las Cortes Generales de 12 de marzo de 2019).
} 
quienes las impulsaron empiezan a plantearse si con la que está cayendo ${ }^{3}$ deben los parlamentos dedicarles su atención y esfuerzo. Aunque son cuestiones distintas, ambas están estrechamente relacionadas y la respuesta que se dé a la primera ha de servir, de ser válida, para responder a la segunda.

A todas las personas, por el hecho de serlo, nuestra Constitución y nuestras leyes reconocen, efectivamente, un conjunto amplio de derechos fundamentales y de libertades que constituyen un cuerpo normativo en continua expansión, impulsado por textos jurídicos internacionales ${ }^{4}$. Y, repito, este cuerpo normativo se aplica a todas las personas, con independencia de otras cuestiones, como pregona el principio de igualdad ante la ley. Como es bien conocido, no es este principio formal el que se ve afectado cuando las normas jurídicas con pretensión de generalidad y que se dirigen y vinculan a todas las personas por igual se aplican a colectivos que padecen discriminación.

Uno de los sectores sociales que mayor discriminación padece, histórica y actualmente, es el de las personas del colectivo LGTBI. En consecuencia, y sin necesidad de mayores explicaciones, por innecesarias ${ }^{5}$, la discriminación de hecho que sufre este colectivo en esta nuestra sociedad puede justificar-como ha sucedido ya con otros colectivos- el reconocimiento legal expreso de dicha discriminación y la también expresa mención y enumeración de aquellos derechos constitucionalmente reconocidos y que, sin embargo, no son efectivamente aplicados; lo que se materializa en situaciones vitales de discriminación y vulnerabilidad ${ }^{6}$, cuando no de odio ${ }^{7}$. En definitiva, esta real diferencia de trato explica, y creo que también justifica, las denominadas leyes $L G T B I$, que se presentan como una demanda de auxilio de un colectivo hacia la sociedad que le acoge. Desde luego, esta es la primera impresión que se extrae de la lectura de muchas de estas leyes: el anhelo de que la letra escrita

\footnotetext{
${ }^{3}$ En mayo de 2020, fecha en que se está redactando este artículo, España se encuentra bajo un estricto estado de alarma que ha determinado el confinamiento de los ciudadanos en sus domicilios desde el día 14 de marzo. En estos momentos, las duras medidas de aislamiento empiezan a relajarse, pero existen grandes temores de rebrotes y la seguridad de que los riesgos para la salud se mantienen y de que solo estamos en las primeras fases de lucha contra la COVID-19. En este sentido, empieza a extenderse la idea de que, tras la práctica paralización de los parlamentos (autonómicos y nacional), la vuelta a la nueva normalidad va a seguir restringiendo la actividad legislativa, de modo que habrán de reservarse los esfuerzos de los parlamentarios para cuestiones más importantes; básicamente, el control al Gobierno. Esta poco explícita opinión significa que, en la situación política actual, con un Gobierno nacional de coalición, sin mayorías absolutas en varias Comunidades Autónomas y una oposición muy centrada en el desgaste del Gobierno, que, por otro lado, ha sido quien ha liderado la lucha contra la COVID-19, el futuro inmediato de los parlamentos parece que será el del campo de batalla político, con la excepción de la aprobación de las necesarias modificaciones a los presupuestos y de leyes muy centradas en el impulso de la economía.

${ }^{4}$ Sobre este tema me remito a lo dicho en De la Cuesta Aguado, P.M. (2001). Persona, dignidad y Derecho penal. En L. A. Arroyo Zapatero/ I. Berdugo Gómez de la Torre (Coord.), Libro Homenaje al Dr. Marino Barbero Santos: "in memoriam", vol. 1 (pp. 209-228). Cuenca, España: Universidad de CastillaLa Mancha, passim.

${ }^{5}$ En cualquier caso, y a título de ejemplo, pueden verse: Leyes y prácticas discriminatorias y actos de violencia cometidos contra personas por su orientación sexual e identidad de género. Informe del Alto Comisionado de las Naciones Unidas para los Derechos Humanos de 17 de noviembre de 2011, recuperado de https://www.ohchr.org/Documents/Issues/Discrimination/A.HRC.19.41 spanish.pdf [citado: 11 de mayo de 2020] o el Informe Anual 2018, de Lilga, recuperado de https://ilga.org/downloads/ILGA Informe Anual 2018 esp web.pdf, y el Informe Anual 2019, recuperado de https://ilga.org/downloads/ILGA Homofobia de Estado 2019.pdf [ambos citados: 11 de mayo de 2020].

${ }^{6}$ Puede verse García Albertos, M. (2018). Mayores y diversidad sexual: entre la visibilidad y el derecho a la indiferencia. Revista Prisma Social, 21. Recuperado de https://dialnet.unirioja.es/ejemplar/494702 [citado: 11 de mayo de 2020].

7 Las estadísticas sobre los delitos de odio en España pueden encontrarse en http://www.interior.gob.es/web/servicios-al-ciudadano/delitos-de-odio/estadisticas [citado: 11 de mayo de 2020]. Con todas las precauciones, puede observarse que entre los colectivos que más delitos de odio padecen se encuentra el colectivo LGBI.
} 
en la Ley acabe con la discriminación real en la calle. Y, junto a lo anterior, una clara finalidad didáctica dirigida a la sociedad en su conjunto, por una parte, y a sectores individualizados, por otra -Sanidad, Educación, Universidades, etc.-.

Sobre estas cuestiones volveremos más adelante, pero, en definitiva, la discriminación y vulnerabilidad que padece el colectivo justifica la necesidad de las leyes. Si esto es así, si las leyes LGTBI son necesarias para ayudar a paliar estas situaciones, también lo son, incluso más, en graves situaciones de crisis social, sanitaria y económica como la provocada por la pandemia de la COVID-19. Más aún, precisamente en situaciones de tensión social -como la que previsiblemente padecerá nuestra sociedad- es cuando los colectivos vulnerables, como este, más padecen la violencia y el odio.

Por lo tanto, las preguntas sobre la necesidad de las leyes LGTBI y la oportunidad de su aprobación en estos momentos han de recibir respuesta positiva, porque no solo es necesario, sino que nuestra sociedad democrática no debe renunciar a garantizar a todos los ciudadanos un trato igual, respetuoso con los derechos que les otorgan las leyes y unas condiciones de vida dignas. Y si esto es necesario en tiempos de calma, más aún lo es en tiempos convulsos.

\section{Impulso político y racionalidad jurídica}

Hemos adelantado que las así denominadas leyes $L G T B I$, tienen dos objetivos: contribuir a garantizar la igualdad de trato en todos los ámbitos de la vida a las personas que pertenecen al colectivo y mostrar a la sociedad las necesidades, discriminación y carencias que lo convierten en vulnerable.

Desde luego que ambos objetivos no juegan idéntico papel, pues la finalidad didáctica, en realidad es el medio para la obtención de la igualdad. Pero, en la práctica, la unión de ambos, unido al desconocimiento generalizado de la realidad LGTBI y, específicamente, trans, a los prejuicios culturales e ideológicos contra el colectivo y al desinterés, más o menos explícito, de los órganos de creación y control jurídico de las Administraciones -léase, cuerpos de letrados y asesores jurídicos-, hace que las leyes aprobadas adolezcan de serias carencias técnicas. O, dicho de otra forma, son leyes -las aprobadas- que han contado con el impulso político de los grupos de defensa de los derechos del colectivo, muy activos, y los grupos parlamentarios y partidos políticos, salvo la extrema derecha, en general, pero, el statu quo sigue manteniendo sus reservas, lo que se ha manifestado en la ruptura entre impulso político y racionalidad jurídica; binomio imprescindible para hacer buenas leyes, a su vez imprescindibles para un correcto, eficiente y democrático orden social.

Entre las carencias técnicas sobresalen dos grupos de ellas: las derivadas de la falta de competencia y las relacionadas con la técnica jurídica utilizada.

\subsection{Modalidades de leyes LGTBI}

Las leyes autonómicas se han ido dictando, como hemos visto, como consecuencia del impulso de los colectivos defensores de los derechos de las personas LGTBI ante las dificultades para conseguir una ley estatal -que sería lo adecuado-. Son numerosas las demandas y los ámbitos en los que se manifiesta la discriminación por razón de orientación sexual, identidad sexual o de género o expresión de género, pero, es el ámbito de la realidad trans donde las reclamaciones adquieren mayor 
urgencia. Ello ha motivado que, en el panorama legislativo autonómico ${ }^{8}$, se puedan distinguir dos grupos de leyes por razón de la materia: Comunidades Autónomas que optan por leyes generalistas que abordan todos los problemas del colectivo y Comunidades Autónomas que optan por leyes específicas para el colectivo trans.

\subsection{Exceso competencial}

Ante la falta de una ley estatal, ambas modalidades de leyes se enfrentan al mismo problema: suplir con leyes autonómicas competencias que son nacionales.

Así, es habitual que tipifiquen como infracciones administrativas lo que son conductas que ya están sancionadas como delito, si bien, cierto es, con escasa o nula aplicación práctica. Esta falta de aplicación de los tipos penales se debe principalmente al desconocimiento de la realidad y a las prevenciones (cuando no prejuicios o criminalización ideológica) de los operadores jurídicos. A ello se une el hecho de que, en ocasiones, los delitos más específicos contra la discriminación tienden a transgredir los principios básicos del Derecho penal garantista y, en su afán por facilitar la persecución de los casos de discriminación más graves y sangrantes, acaban extendiendo exageradamente el ámbito de lo típico, lo que, ahora desde una perspectiva de la racionalidad jurídico-penal, también generan una cierta prevención.

Este fenómeno no es desconocido para el Derecho penal: lo hemos padecido siempre que ha intentado entrar a regular nuevos valores ajenos a los propios de la sociedad cristiano-liberal. Similares prevenciones y déficits de aplicación práctica padecieron los delitos contra el medio ambiente, la ordenación del territorio o los delitos contra la violencia de género. De hecho, la tipificación y aplicación judicial de estos últimos pueden servirnos como modelo comparativo -también porque algunos de ellos sirven contra la discriminación de género y la discriminación por razón de orientación o identidad sexual e identidad de género-.

Por ello, en términos estrictamente jurídico penales, es preciso cuidar la corrección técnica de los tipos penales ${ }^{9}$, pues no puede olvidarse como los delitos contra la violencia de género han generado no solo una enorme controversia, sino una falsa apariencia de protección, por un lado, y de injusta criminalización de los hombres ${ }^{10}$, por otro, cuando, líneas jurisprudenciales como la aplicada al fenómeno de las denominadas "peleas mutuas» acaban sancionando más gravemente a la mujer ${ }^{11}$.

Pero, el exceso en la asunción de competencias está provocada por las dificultades para adecuar los datos registrales a la identidad de género o sexual de las personas.

El derecho a la propia imagen, al propio nombre y a que la persona sea identificada por terceros por el nombre que desea, según entiendo, viene amparado

\footnotetext{
8 También en las Proposiciones de Ley presentadas ante el Parlamento de España.

${ }^{9}$ Demanda que, por cierto, no es exclusiva de este grupo de delitos, sino que se puede hacer extensiva a todas las reformas penales del nuevo milenio.

10 Sobre esta cuestión, más ampliamente, De la Cuesta Aguado, P. M. (2020). Violencia de género: heteroprotección y autoprotección. En R. Castillejo Manzanares/ C. Alonso Delgado (Dir.), El género y el sistema de (in)justicia (pp. 39-64). Valencia, España: Tirant Lo Blanch.

11 Sobre esta cuestión puede verse, con análisis jurisprudencial, Manjón-Cabeza Olmeda, A. (2010). Dominación y machismo: ¿quién decide? (a propósito de la STC 41/2010, de 22 de julio, que considera conforme a la Constitución el art. 148.4. CP). Diario La Ley, 7496, passim. También, San Millán Fernández, B. (2019). Estudio dogmático y jurisprudencial sobre la agravante de discriminación por razones de género. Estudios penales y criminológicos, 39, pp.325-ss.; o De la Cuesta Aguado, P. M. (2020). Violencia de género: heteroprotección y autoprotección, cit., passim.
} 
directamente, sin perjuicio de otras normas de menor rango, por la Constitución Española en sus artículos 10 -dignidad de la persona y libre desarrollo de la personalidad-; art. 15 -derecho a la integridad moral, entendida como el respeto por parte del Ordenamiento Jurídico de las más íntimas decisiones acerca de uno mismoy art. 18.1 -derecho al honor y a la propia imagen-. Además, el Tribunal Europeo de Derechos Humanos, en la sentencia dictada en el asunto A.P. Garçon y Nicot contra Francia, de 6 de abril de 2017, ha reconocido que elementos tales como el nombre, entre otros, caen dentro de la esfera personal protegida por el art. 8 del Convenio Europeo de Derechos Humanos y, en tal sentido, se ha pronunciado también la sentencia del Pleno del Tribunal Supremo 99/2019, de 18 de julio. Por su parte, la Instrucción de 23 de octubre de 2018, de la Dirección General de los Registros y del Notariado, sobre cambio de nombre en el Registro Civil de personas transexuales, en su artículo primero ${ }^{12}$ reconoce el derecho al cambio de los datos registrales correspondientes al nombre y al sexo, sin necesidad de acreditar mediante certificado médico o de psicólogo patología alguna.

Sin embargo, lo cierto es que, hoy en día, los registros civiles más aperturistas, siguen exigiendo certificado de disforia de género para el cambio de nombre y de tratamiento médico por dos años para el cambio registral del sexo. Ante esta situación, los colectivos reclaman la creación de registros en las Comunidades Autónomas que permitan a las personas utilizar su nombre elegido cuando se dirigen a la Administración Pública, con independencia del nombre que aparece en el Documento Nacional de Identidad. Esta cuestión es sumamente controvertida, por su utilidad, primero; por las dificultades y el alto coste para la creación de un registro de esas características, después; porque no se puede garantizar que en un futuro nuestra democracia no se vea comprometida o sustituida por un régimen autoritario, en cuyo caso, tener agrupadas en un fichero a personas históricamente perseguidas, es muy peligroso; y, finalmente, porque puede exceder de la competencia de las Comunidades Autónomas. De ahí que, una vez aprobadas tales leyes autonómicas, a continuación, se haya firmado un acuerdo con el Gobierno central en el que se reconoce que tales leyes se aplicarán, exclusivamente, dentro de las competencias de la correspondiente Comunidad Autónoma, lo que jurídicamente no parece más que la constatación de lo obvio, pero, que, en la práctica, deja sin efecto las mayores aspiraciones del colectivo y una de las medidas estrella de las leyes autonómicas ${ }^{13}$.

\subsection{Carencias derivadas de la técnica jurídica utilizada}

En general, se trata de leyes que repiten, a veces, innecesariamente conceptos; que no definen correctamente otros; que se caracterizan por la enunciación de principios

\footnotetext{
12 «En el supuesto de que un mayor de edad o un menor emancipado solicitara el cambio de nombre, para la asignación de uno correspondiente al sexo diferente del resultante de la inscripción de nacimiento, tal solicitud será atendida, con tal de que ante el encargado del Registro Civil, o bien en documento público, el solicitante declare que se siente del sexo correspondiente al nombre solicitado, y que no le es posible obtener el cambio de la inscripción de su sexo en el Registro Civil, por no cumplir los requisitos del art. 4 de la Ley 3/2007, de 15 de marzo, reguladora de la rectificación registral de la mención relativa al sexo de las personas».

13 Entre otras y como ejemplo: Resolución de 12 de abril de 2013, de la Secretaría General de Coordinación Autonómica y Local, por la que se publica el Acuerdo de la Comisión Bilateral de Cooperación Administración del Estado/ Administración de la Comunidad Autónoma del País Vasco en relación con la Ley del País Vasco 14/2012, de 28 de junio, de no discriminación por motivos de identidad de género y de reconocimiento de los derechos de las personas transexuales (BOE 99, 25/04/2013, BOPV 79, 25/04/2013) o Resolución de 30 de abril de 2015, de la Secretaría General de Coordinación Autonómica y Local, por la que se publica el Acuerdo de la Subcomisión de Seguimiento Normativo, Prevención y Solución de Controversias de la Comisión Bilateral de Cooperación Administración General del Estado-Comunidad Autónoma de Andalucía en relación con la Ley 2/2014, de 8 de julio, integral para la no discriminación por motivos de identidad de género y reconocimiento de los derechos de las personas transexuales de Andalucía (BOE 118, 18/05/2015).
} 
genéricos carentes de medidas prácticas que los acompañen, en parte, porque tales medidas y su aplicación corresponde a los reglamentos. Aunque, como parece que subyace latente la idea de que tales reglamentos ni están ni se les espera, las leyes se empeñan, o bien en bajar a ámbitos excesivamente concretos, o bien en enunciar, una y otra vez, principios y derechos. Este ímprobo esfuerzo por hacer que la letra de la Ley sustituya la realidad, tiene efectos perniciosos porque dota de argumentos formales ( $\mathrm{y}$ aparentemente racionales para quien desconozca la realidad de discriminación efectiva) a quienes pretenden atacar estas leyes.

En lo que sigue, analizaremos algunas de estas cuestiones con la finalidad de ofrecer soluciones a los problemas planteados; soluciones que, a falta de la necesaria ley estatal, puedan hacer efectivos los principios de igualdad y no discriminación que se tratan de materializar. Ello no obsta para que las reflexiones que ahora siguen también puedan ser útiles a efectos de la tramitación parlamentaria en el Congreso de los Diputados del actual o futuros proyectos o proposiciones de ley en esta materia ${ }^{14}$.

\subsection{El problema terminológico}

\subsubsection{Cuestiones generales}

Una de las cuestiones más controvertidas, desde el punto de vista de la técnica jurídica, que es, además, común a todas las leyes y proyectos o proposiciones de ley sobre la materia, es la de los términos utilizados para designar a la realidad que trata de definir y la necesidad de incorporar catálogos de definiciones en los primeros artículos de los textos legales.

Desde luego puede entenderse la finalidad de esta estrategia: potenciar y beneficiarse de los efectos didácticos de la ley. Pero, desde una perspectiva de técnica jurídica, se plantean algunas objeciones; pues, aunque las leyes puedan contener definiciones, estas han de tener una concreta finalidad a los efectos de la ley, pero definir para enseñar es más propio de reglamentos o de órdenes. Podría, en su caso, incluso, hacerse mediante un anexo al propio texto normativo, pero, introducir catálogos de términos en un texto legal tiene graves efectos distorsionadores ${ }^{15}$.

El primero de ellos deriva de que se están incorporando a la leyes o proyectos (o proposiciones) términos que ya son controvertidos en otros ámbitos. Así sucede, por ejemplo, con el término «transexual» para referirse a una persona que no se siente identificada con el género que el sistema social y jurídico asocia a sus caracteres sexuales externos. El término «transexual» aparece definido en algunas leyes, no siempre en idénticos términos, y en el Diccionario de la Real Academia. Esta situación puede llevar al absurdo de que el mismo término pueda tener un significado diferente según la Comunidad Autónoma y, además, otro para la RAE que es la que define el significado de las palabras en la lengua con la que nos comunicamos los ciudadanos. Esto, desde luego y con independencia de las connotaciones que conlleve en el ámbito médico, no es deseable y puede tener el efecto de forzar continuas reformas de las propias leyes para adecuar los conceptos al devenir social o científico-como

\footnotetext{
14 Véase nota 1.

15 A título de ejemplo, lo hace así, entre otras, la Ley 11/2014, de 10 de octubre, para garantizar los derechos de lesbianas, gais, bisexuales, transgéneros e intersexuales y para erradicar la homofobia, la bifobia y la transfobia, de Cataluña.
} 
ha sucedido ya, por ejemplo, con la Ley Vasca ${ }^{16}-y$, además, es uno de los argumentos que utilizan los detractores de estas leyes para atacarlas.

No es este el único ejemplo que podemos ofrecer sobre diversidad de definiciones sobre un mismo término, pero sí que sirve para ejemplificar el problema que queremos poner de manifiesto. En resumen: es necesario ser muy restrictivo con la incorporación de definiciones legales a las leyes LGTBI. Ello no significa que en ningún caso quepa incorporar una definición a los efectos de la ley, sino que es preciso que, cuando se haga, sea, primero necesario y, segundo, no contradiga el sentido ordinario, en el lenguaje no jurídico, del término.

La necesidad de incorporar al texto legal una definición puede venir determinada, en principio, bien por razones didácticas derivadas de la función de la propia ley; bien porque sea preciso concretar el significado de un término que, posteriormente, será utilizado con efectos jurídicos. Aquí se pone, también, de manifiesto la importancia de una ley estatal que sea la encargada de definir conceptos tales como "discriminación indirecta» o «discriminación múltiple», si se aceptara que su incorporación al texto legal tiene como finalidad denunciar que tales situaciones existen y que han de servir como criterios objetivos para detectar y definir situaciones de vulnerabilidad.

Pero, a ser posible, se debería prescindir de términos que no estén contenidos en otros preceptos de la propia ley, sin perjuicio de que se habiliten mandatos para que reglamentariamente se haga, con fines de difusión en el ámbito administrativo u otros, o que se incorpore, incluso a la propia ley, algún anexo con finalidades aclaratorias de conceptos con fines interpretativos.

En cualquier caso, la definición que se ofrezca normativamente a términos que proceden del lenguaje ordinario, médico o biológico, no debería alejarse de ellos ni, por supuesto, intentar impedir su evolución, primero, porque sería pretensión vana, y segundo, porque la definición jurídica puede quedar pronto alejada del significado no jurídico de los términos, lo que es fácil que suceda en un ámbito en el que el conocimiento está avanzando en términos exponenciales.

\subsubsection{Sobre el Título de la Ley y lo que ello conlleva}

Una de las cuestiones que más llama la atención es la diversidad terminológica para designar a las singularidades de las personas que las citadas leyes quieren proteger. Esto se pone de manifiesto ya en el propio título de las diversas leyes, proyectos o proposiciones de ley, especialmente en aquellas cuyo objetivo no se reduce a las personas trans. Así, a modo de ejemplo y sin ánimo de exhaustividad, en el ámbito estatal la Proposición de ley 122/00097, de 12 de mayo 2017, se titula Proposición de

\footnotetext{
${ }^{16}$ La Ley 9/2019, de 27 de junio, de modificación de la Ley 14/2012, de 28 de junio, de no discriminación por motivos de identidad de género y de reconocimiento de los derechos de las personas transexuales, contiene un único artículo del siguiente tenor: «Artículo único. Se modifica el artículo 3 de la Ley 14/2012, de 28 de junio, de no discriminación por motivos de identidad de género y de reconocimiento de los derechos de las personas transexuales, que queda redactado en los siguientes términos:

Artículo 3. -Personas transexuales. La noción de transexualidad hace referencia a la situación por la que el sexo que se le supuso al nacer a una persona, en atención a sus genitales, no coincide con el sexo que esa persona siente y sabe que es. La transexualidad, por lo tanto, solo puede conocerse a través de la escucha de lo que la persona libremente expresa y, al igual que la identidad sexual, no se puede diagnosticar. No es una enfermedad, un trastorno o una anomalía, sino que forma parte de la diversidad humana. En consecuencia, a los efectos de esta ley, la consideración de persona transexual se regirá por el derecho a la libre autodeterminación de la identidad sexual. Este derecho no podrá ser limitado, restringido, dificultado o excluido debiendo interponerse y aplicarse las normas siempre a favor del libre y pleno ejercicio del mismo. Las personas transexuales podrán acogerse a lo establecido por la presente ley sin necesidad de un diagnóstico o informe psiquiátrico, psicológico ni tratamiento médico».
} 
Ley contra la discriminación por orientación sexual, identidad o expresión de género y características sexuales, y de igualdad social de lesbianas, gais, bisexuales, transexuales, transgénero e intersexuales ${ }^{17}$. Por su parte, una nueva Proposición de Ley, esta vez de 2018, es intitulada como Proposición de Ley sobre la protección jurídica de las personas trans y el derecho a la libre determinación de la identidad sexual y expresión de género ${ }^{18}$. Estas leyes representan las dos orientaciones legislativas en la materia a que hemos hecho referencia con anterioridad, pero sirven para mostrar la ausencia de uniformidad terminológica. Esta situación se reproduce en el ámbito de las Comunidades Autónomas. Así, la ley andaluza opta por «identidad de género» y "personas transexuales» ${ }^{19}$; Aragón prefiere «orientación sexual, expresión e identidad de género» ${ }^{20}$; Valencia, «personas LGTBI» ${ }^{21}$; y, por finalizar este breve repaso, Cataluña, «lesbianas, gays, bisexuales, transgéneros e intersexuales y para erradicar la homofobia, la bifobia y la transfobia» ${ }^{22}$.

Esta variedad terminológica se suele reproducir en los preceptos de los propios textos legales, que no siempre utilizan la misma terminología para definir las idénticas identidades, lo que puede generar confusión al intérprete.

Si nos fijamos en textos jurídicos internacionales, los PRINCIPIOS DE YOGYAKARTA utilizan una expresión mucho más depurada y simplificada: «orientación sexual e identidad de género». Sin perjuicio de que esta más genérica y amplia designación parece preferible, quizá en la actualidad se perciba como insuficiente -recuérdese que fue aprobado en 2007-. De ahí que, en nuestra opinión, manteniendo este criterio de generalidad y simplicidad, se recomienda referirse a la pluralidad de supuestos que se encuentran -o pueden encontrarse- en el colectivo LGTBI con las siguientes cuatro expresiones: orientación sexual, identidad sexual, identidad de género y expresión de género. En este punto, podría parecer que «identidad sexual» e «identidad de género» hacen referencia a una misma situación, sin embargo, hay supuestos de intersexualidad que no se encontrarían incluidos en la expresión «identidad de género», por lo que consideramos que es preferible mantener, también en los textos legales, ambas denominaciones.

Y, desde luego, en cuanto al título de las diversas leyes, sería preferible, desde un punto de vista técnico, también reducir la complejidad y el tamaño de los títulos. Cierto es que las leyes que optan por una denominación compleja acaban convirtiéndose en términos coloquiales en «leyes LGTBI». Aun así, una denominación más correcta, simple e identificativa de las finalidades de protección sería de gran ayuda para su integración en la cultura colectiva. En este sentido, consideramos que las leyes, en su «nombre», deberían hacer referencia a la protección de Derechos Humanos - pues, de eso, y no de otra cosa, se trata- relacionados con la diversidad sexual y de género.

\footnotetext{
17 Publicada en el Boletín Oficial de las Cortes Generales de 12 de mayo de 2017.

18 Proposición de ley 122/000191 sobre la protección jurídica de las personas trans y el derecho a la libre determinación de la identidad sexual y expresión de género, de 12 de mayo de 2017 (Boletín Oficial de las Cortes Generales de 2 de marzo de 2018).

${ }^{19}$ Ley $2 / 2014$, de 8 de julio, integral para la no discriminación por motivos de identidad de género y reconocimiento de los derechos de las personas transexuales de Andalucía.

${ }^{20}$ Ley 18/2018, de 20 de diciembre, de igualdad y protección integral contra la discriminación por razón de orientación sexual, expresión e identidad de género en la Comunidad Autónoma de Aragón.

${ }^{21}$ Ley $23 / 2018$, de 29 de noviembre, de igualdad de las personas LGTBI.

22 Ley 11/2014, de 10 de octubre, para garantizar los derechos de lesbianas, gais, bisexuales, transgéneros e intersexuales y para erradicar la homofobia, la bifobia y la transfobia.
} 


\section{Igualdad, no discriminación y acción positiva}

Los principios de igualdad -material-y de no discriminación, no solo fundamentan, sino que también vertebran las leyes LGTBI. Tales principios se enuncian con carácter general y, también, sectorialmente, en el ámbito educativo, en el sanitario; en el del empleo; en el deportivo, etc.

Tales principios, por otro lado, son inmanentes a un sistema democrático y que legalmente están garantizados por la Constitución, tratados internacionales firmados por España, leyes diversas y cuentan con el aval jurisprudencial del Tribunal Europeo de Derechos Humanos y nuestro Tribunal Constitucional. De modo que, la mera enunciación y proclamación de tales principios solo surte efectos didácticos y de recordatorio frente a la discriminación del colectivo, salvo que se adopten medidas de aplicación efectiva en los distintos ámbitos. Y aquí es donde surgen, precisamente, los problemas; porque, por un lado, las medidas de acción positiva de un texto legal generan enorme reticencias $y$, por otro, las medidas que efectivamente adoptan los textos legales que hemos analizado son, propiamente, medidas que, en una correcta técnica jurídica, deberían adoptarse mediante normas administrativas; es decir, reglamentariamente ${ }^{23}$.

Así, entre las medidas propiamente legislativas habría que enunciar las de acción positiva. Entre estas resaltan por su significado, importancia y dificultad las siguientes:

a) medidas de acción positiva en el acceso a la función pública.

b) medidas relacionadas con pruebas de acceso a la función pública que tomen en consideración características físicas vinculadas al sexo biológico desde una perspectiva exclusivamente binaria (es decir, que distinga entre «hombre» y «mujer» $y$ todas las personas deban adscribirse a ellos en función del cromosoma $Y$ y sus efectos).

c) medidas de acción positiva en el deporte.

d) medidas de reconocimiento de tratamientos específicos para la adecuación de los caracteres sexuales externos con el sexo o género sentido.

Vaya por adelantado lo controvertido de todas y cada una de estas posibles medidas; vaya por adelantado, también, que, si no se adoptan, la justificación de la labor legislativa queda muy mermada. Reitero, en este momento, algo ya advertido: la mayoría, si no todas, estas medidas deben ser adoptadas por una ley nacional y, todo lo más, posteriormente adaptadas a las necesidades autonómicas por los distintos parlamentos autonómicos. No es así como se está actuando y esto genera, desde luego, tensiones dentro del propio Ordenamiento Jurídico.

\subsection{Medidas de acción positiva en el acceso al empleo público}

Como decíamos con anterioridad, las grandes afirmaciones de igualdad, no discriminación y los genéricos mandatos a las Administraciones Públicas para que adopten medidas de acción positiva quedarán en agua de borrajas si las propias leyes

\footnotetext{
${ }^{23}$ Reitero que las razones de tal confusión de órdenes, entre lo propio de la más genérica regulación legal y la más concreta del reglamento, se debe a que grupos parlamentarios y colectivo son conscientes de que las concretas medidas que no se adopten en sede parlamentaria -aunque sean tan concretas que debieran ser objeto de regulación reglamentaria- no se adoptarán en modo alguno, ante las dificultades y reticencias con que se encuentra la Administración Pública para ello.
} 
no imponen medidas en concreto. $\mathrm{Y}$, desde luego, entre otras posibles, las que no deberían faltar son las medidas de acción positiva en el acceso a la función pública mediante cuotas de reserva de empleo, como sucede con otros colectivos vulnerables; aunque, por supuesto, habrá que buscar fórmulas lo suficientemente seguras como para que surtan los efectos previstos y generen confianza -en la población, en general, y en su validez a los efectos previstos, en particular-.

No negaremos, sin embargo, que argumentos en contra caben muchos, especialmente en un mercado laboral precario e insuficiente. Pero, si realmente se cree el punto de partida, la necesidad y las razones que justifican la existencia de estas leyes que nos ocupan -es decir, que nos encontramos ante un colectivo muy vulnerable-, las cuotas de reserva son consecuencia necesaria, de lo que se deduce que cualquier argumento en contra, de hecho, niega la premisa mayor: la vulnerabilidad en la que se encuentran algunas personas de este colectivo porque es la propia sociedad, precisamente, la que les coloca en esa situación ${ }^{24}$. A este respecto es preciso recordar que, en la actualidad, no todos los sujetos del colectivo padecen idéntica discriminación, sino que este problema se plantea, específicamente, en relación con las personas trans ${ }^{25}$.

Las cuotas de reserva pueden, sin embargo, contradecir el derecho a la privacidad, lo que exigiría reserva sobre los datos personales de los solicitantes. Para evitar las previsibles suspicacias acerca de fraudes en la condición de la persona -0 sea, que alguien «no trans» se hiciera pasar por «trans» para acceder a las cuotas reservadas-, se podría exigir demostración de las condiciones objetivas de vulnerabilidad, siempre y cuando ello no implique una prueba imposible o un atentado contra la dignidad e intimidad de las personas. Así, podría considerarse prueba objetiva de situación de vulnerabilidad la acreditación de haber padecido ataques violentos, insultos, etc., como consecuencia de la orientación sexual, de la identidad sexual o de la identidad de género; certificados médicos o psicológicos que acrediten los efectos graves que la situación de discriminación produce, etc.

Desde luego que estas medidas, probablemente muy controvertidas, no resolverían el problema del desempleo y de las dificultades de acceso a puestos de trabajo del colectivo, de la misma manera que no los resuelven con otros colectivos especialmente vulnerables, pero, en alguna medida ayudan a paliarlos y, sobre todo, ayudan a transmitir la imagen de la capacidad para trabajar de estas personas, lo que en el mercado de trabajo es esencial.

\subsection{Sobre las pruebas físicas vinculadas al sexo biológico}

Algunas plazas de empleo público, generalmente vinculadas con la seguridad del Estado (Fuerzas y Cuerpos de Seguridad) o las emergencias (bomberos, etc.), pueden exigir la superación de pruebas físicas que consisten en la realización de

\footnotetext{
${ }^{24}$ Puede verse Belsué Guillorme, K. (2011). Sexo, género y transexualidad: de los desafíos teóricos a las debilidades de la legislación española. Acciones e investigaciones sociales, 29, pp. 7-32.

${ }^{25}$ En general, aunque es difícil encontrar fuentes fiables, se puede afirmar que el colectivo alcanza altísimos índices de desempleo en España, que podrían llegar incluso al $80 \%$. Las mujeres trans se ven especialmente afectadas. Muchas de ellas acaban dedicándose a la prostitución como única forma de subsistencia. Estos datos no están, en nuestra opinión, suficientemente contrastados, lo que no significa, sin embargo, que estén alejados de la realidad. En el conjunto de Europa, el desempleo se sitúa en el $50 \%$, según el documento Ser «trans» en la UE. Análisis comparativo de los datos de la encuesta a personas LGBT en la UE. Resumen recuperado de https://fra.europa.eu/sites/default/files/fra-2015being-trans-eu-comparative-summary es.pdf [citado: 10 de mayo de 2020]. Estos datos tampoco son significativos de la situación en España que adolece de mayor tasa de paro que la media de la UE y, además, incluye entre los empleados a personas que perciben pensiones públicas, pero, en cualquier caso, es indicativo de que los índices de desempleo son altísimos.
} 
determinados ejercicios o la superación de objetivos prefijados de esfuerzo físico. Tales ejercicios se condicionan y evalúan en función de la condición manifestada por los genitales externos al nacer (hombre o mujer), en general, en relación con otros parámetros como la altura.

La distinción de los baremos según el sexo ya fue un gran avance, pues los baremos tradicionales median criterios basados en modelos masculinos. Sin embargo, este modelo es, actualmente, insuficiente y, además, existen criterios médicos que pueden ajustar y hacer más equilibrada y justa la evaluación de las condiciones físicas ${ }^{26}$. Por lo tanto, sería importante repensar lo que miden los baremos y la necesidad de su vinculación con el sexo.

Téngase en cuenta que tales baremos se hacen sobre generalizaciones y medias. Por ejemplo, se considera que la altura media de las mujeres es 1,62 y la de los hombres, 1,72; que las mujeres entre 1,62 y 1,70, hacen una media de $5 \mathrm{~km}$. por hora, etc., y, a partir de estos cálculos se construyen baremos por los que se evalúa a todas las personas. A falta de otros criterios, desde luego que estos son objetivos; pero, la cuestión es que hoy en día tenemos la posibilidad de precisar mejor en base a la consideración de otros datos más objetivos y más atinados. Baste como ejemplo recordar que es normal utilizar máquinas que miden y relacionan un variado número de parámetros para determinar las condiciones físicas que se quieren analizar (por ejemplo, capacidad muscular y parámetros como la altura, el peso, capacidad respiratoria, etc.). Quiero decir con ello que, hoy en día, podemos utilizar parámetros más sensibles y ajustados para definir la capacidad física de una persona que aquellos basados en uno o dos criterios (la altura y el sexo); parámetros más sensibles y que permiten valorar conjuntamente distintos datos por lo que precisan mejor la capacidad física $-\mathrm{y}$ ello con independencia del cromosoma $\mathrm{Y}-$.

La adopción de criterios científicos mejor adaptados a las necesidades de la evaluación física tendrá efectos beneficiosos para todas las personas, pero para las personas trans tendrá la enorme ventaja de que evaluará realmente sus condiciones físicas, sin necesidad de que sean sometidas a indeseables privaciones de su intimidad y, de cara a terceros, los criterios de evaluación seguirán siendo objetivos, con lo que se evitarán las críticas fáciles y las, también fáciles, acusaciones de fraude.

\subsection{De la acción positiva en el deporte}

Algo similar sucede en el ejercicio del deporte. Desde luego que no es este el momento de entrar a debatir el problema que se plantea en las competiciones deportivas profesionales, sobre todo cuando de leyes autonómicas se trata. $\mathrm{Ni}$ siquiera lo plantearé en otras competiciones deportivas, aunque esta es una cuestión abierta y no se debe cerrar en falso si, como apuntan los datos, entre $5 \%$ y un $10 \%$ de la población no se identifica con el sexo asignado al nacer.

Pero, desde luego, algo que debe resolverse legalmente es la posibilidad de que las personas puedan hacer deporte, cuando es una forma de juego, de diversión y esparcimiento, de socialización sin que ello signifique negarse a sí mismas o someterse a intolerables rupturas de la privacidad. Y, repito, no todo deporte es competición. No planteo este problema en el ámbito de la competición, pues no es

\footnotetext{
${ }^{26}$ Esto será así, además, siempre y cuando se siguiera considerando imprescindible una determinada condición física o potencia muscular, desde luego innecesaria para investigar crímenes o para hacer tareas de oficina y que, si no se mantienen en el tiempo, evidentemente, se pierden. Desde luego este no es objeto de este trabajo, pero sí pone de manifiesto que, quizá, la sociedad tecnológica ha superado $\mathrm{o}$, al menos, permitido superar algunos criterios que, en otros tiempos, parecían imprescindibles. $Y$ todo ello en beneficio de todas las personas y, por supuesto, de toda la sociedad.
} 
este ni el foro, ni el objetivo. Pero, cuando el deporte no sea competición -jal menos cuando no sea competición!- no existen argumentos para impedir el desarrollo y la manifestación de la propia identidad.

\section{Reflexiones finales y sobre la necesidad de la identificación del propio sexo}

Estas últimas reflexiones ponen de manifiesto la inconveniencia de que las personas tengamos que identificarnos ante las Administraciones Públicas o en el ejercicio de nuestras actividades cotidianas en función de criterios que no implican en la actualidad un diferente estatuto jurídico.

Me explico: en otros momentos históricos, el hecho de ser hombre o ser mujer tenía trascendencia jurídica. Si eras hombre, según la edad, podías gozar de plenos derechos civiles; si eras mujer, nunca gozarías de plenos derechos civiles y dependerías jurídicamente de un hombre. En estas condiciones, era necesario que los documentos con trascendencia jurídica e incluso los actos y negocios jurídicos identificaran el sexo de las personas, pues de ello derivaba su capacidad jurídica. Es decir, cada sexo tenía asignado un diferente estatuto jurídico.

Igualmente, en otros tiempos era importante, a efectos jurídicos, saber si una persona estaba casada o soltera, si era viuda, o, incluso, si era divorciada -aunque no dejo de sospechar que esta última categoría tenía otras finalidades- ${ }^{27}$.

Sin embargo, ninguna de estas situaciones personales, hoy en día, lleva aparejado estatuto jurídico diverso alguno. Es decir, a efectos jurídicos es indiferente el sexo, el estado civil, la viudedad o el constante matrimonio. Si, como digo, ninguna de estas circunstancias, condiciones, estados de las personas, lleva asignado estatuto jurídico distinto al común, porque todos los sexos y los estados civiles tienen igual tratamiento jurídico, no se entiende por qué las personas debemos identificar nuestro sexo o nuestro estado civil ante las Administraciones Públicas o ante otros particulares con quienes contratamos o nos relacionamos con trascendencia jurídica. Por ejemplo, no se entiende por qué para reclamar una prestación ante una Administración Pública, debemos identificar el sexo que se nos asignó al nacer. En concreto, en la vida cotidiana son muy pocos los supuestos en los que el sexo con que se nos identificó al nacer tenga trascendencia jurídica. Si esto es así, las personas deberíamos no tener que revelar nuestro sexo. $Y$ algo similar sucede con el estado civil, aunque son imaginables más supuestos donde este pueda tener trascendencia jurídica. Pero, desde luego, cuando no surtiere efectos jurídicos, no debería exigirse ni, aún, preguntarse.

El abandono de hábitos jurídicos que responden a sistemas jurídicos discriminatorios y lesivos para los Derechos Humanos para adecuarlo a la realidad jurídica actual beneficia a toda la sociedad, por muy extraño que parezca. Desde luego beneficiará a las mujeres que concurran a un puesto de trabajo - dada la actual y evidente discriminación en el empleo que padecen-, ayudará a acabar con la discriminación indirecta, porque jurídicamente somos iguales y no se nos obligará continuamente a recordar que nuestros órganos sexuales nos distinguen. Pero quienes obtendrán una evidente mejora en su calidad de vida serán aquellas personas cuya personalidad no se adecúa al simplista modelo binario que depende de los caracteres sexuales externos.

\footnotetext{
${ }^{27}$ A título de ejemplo, puede verse Pestaña Ruíz, C. (2016). Evolución jurídica de la mujer casada en el sistema matrimonial español de la época preconstitucional, Revista de Estudios Jurídicos, 15. Recuperado de https://revistaselectronicas.ujaen.es/index.php/rej/article/view/3210 [citado: 11 de mayo de 2020].
} 
Desde luego caben muchas opiniones contrarias a esta propuesta, creo que la mayoría de índole ideológico, religioso, etc.; es decir, derivadas de emociones y modos de pensar, todos muy respetables, pero alejados de la racionalidad jurídica de un Estado de Derecho respetuoso con los Derechos Humanos y el principio de igualdad consagrado en nuestra Constitución. Y, en cualquier caso, la necesidad de hacer estadísticas para ayudar a superar situaciones de discriminación 0 vulnerabilidad no puede ser argumento en contra, pues los datos que necesitan tales estadísticas podrían obtenerse de otro modo o, en cualquier caso, podrían ser voluntarios.

Bibliografía

Belsué Guillorme, K. (2011). Sexo, género y transexualidad: de los desafíos teóricos a las debilidades de la legislación española. Acciones e investigaciones sociales, 29, pp. 7-32.

De la Cuesta Aguado, P.M. (2001). Persona, dignidad y Derecho penal. En L. A. Arroyo Zapatero/ I. Berdugo Gómez de la Torre (Coord.), Libro Homenaje al Dr. Marino Barbero Santos: "in memoriam", vol. 1 (pp. 209-228). Cuenca, España: Universidad de Castilla-La Mancha.

De la Cuesta Aguado, P. M. (2020), Violencia de género: heteroprotección y autoprotección. En R. Castillejo Manzanares/ C. Alonso Delgado (Dir.), El género y el sistema de (in)justicia (pp. 39-64). Valencia, España: Tirant Lo Blanch.

European Union Agency for Fundamental Right: Ser «trans» en la UE. Análisis comparativo de los datos de la encuesta a personas LGBT en la UE. Recuperado de https://fra.europa.eu/sites/default/files/fra-2015-being-trans-eu-comparativesummary es.pdf [citado: 10 de mayo de 2020].

García Albertos, M. (2018). Mayores y diversidad sexual: entre la visibilidad y el derecho a la indiferencia. Revista Prisma Social, 21. Recuperado de https://dialnet.unirioja.es/ejemplar/494702 [citado: 11 de mayo de 2020].

ILGA, Informe Anual 2018. Recuperado de https://ilga.org/downloads/ILGA Informe Anual 2018 esp web.pdf [citado: 11 de mayo de 2020].

ILGA, Informe Anual 2019. Recuperado de https://ilga.org/downloads/ ILGA Homofobia de Estado 2019.pdf [citado: 11 de mayo de 2020].

Manjón-Cabeza Olmeda, A. (2010). Dominación y machismo: ¿quién decide? (a propósito de la STC 41/2010, de 22 de julio, que considera conforme a la Constitución el art. 148.4. CP). Diario La Ley, 7496.

San Millán Fernández, B. (2019). Estudio dogmático y jurisprudencial sobre la agravante de discriminación por razones de género. Estudios penales y criminológicos, 39, pp. 303-351.

Pestaña Ruíz, C. (2016). Evolución jurídica de la mujer casada en el sistema matrimonial español de la época preconstitucional. Revista de Estudios Jurídicos, 15. Recuperado de https://revistaselectronicas.ujaen.es/index.php/ rej/article/view/3210 [citado: 11 de mayo de 2020]. 